\title{
Viewpoint
}

\section{Childhood vaccine uptake in Africa: threats, challenges, and opportunities}

\author{
Edward Mbonigaba', David Nderu², Simiao Chen ${ }^{3}$, C. Denkinger ${ }^{4}$, P. Geldsetzer ${ }^{4}$, S. McMahon ${ }^{4}$, Till Bärnighausen ${ }^{4}$ \\ 1 Heidelberg Institute of Global Health, University of Heidelberg, Germany; College of Medicine, School of Public Health- University of Rwanda, \\ Rwanda, ${ }^{2}$ School of Health Sciences, Kirinyaga University, Kirinyaga, Kenya, ${ }^{3}$ Heidelberg Institute of Global Health, University of Heidelberg, \\ Germany; Chinese Academy of Medical Sciences and Peking Union Medical College, China, ${ }^{4}$ Heidelberg Institute of Global Health, University of \\ Heidelberg, Germany \\ Keywords: childhood vaccine, vaccine uptake, immunization, africa \\ https://doi.org/10.29392/001c.26312
}

\section{Journal of Global Health Reports}

Vol. 5, 2021

\begin{abstract}
Childhood vaccination is a highly effective public health intervention for reducing childhood mortality and morbidity. This review discusses the factors that have been shown to influence vaccination uptake in Africa. African countries should develop effective strategies to address failures and challenges faced with vaccination uptake and hesitancy for it to achieve high vaccination coverage and reduction of vaccine preventable diseases.This is particularly important because of the likely short-term decline in foreign aid due to the economic recession arising from the prevailing coronavirus disease 2019 pandemic.
\end{abstract}

Childhood vaccination is regarded as an effective public health intervention for preventing child mortality and reducing morbidity. ${ }^{1}$ Despite of increased global childhood vaccination coverage and uptake observed over the years, Africa is still lagging behind. ${ }^{2}$ Governments and their development partners have made deliberate attempts to improve childhood vaccine uptake and acceptance in resource-limited settings. ${ }^{3}$ In 2000, the Global Alliance for Vaccination and Immunization (GAVI) was established to accelerate vaccination uptake in different parts of the world, particularly where vaccination coverage is still low. Recent World Health Organization (WHO) estimates indicate that vaccines avert $2-3$ million child deaths annually for example, smallpox and polio have been successfully eradicated in Africa through vaccination. ${ }^{4}$ Another notable example where vaccines have had appositive impact is in reduction of measles mortality due to improved mass vaccination campaign. ${ }^{5}$ These improvements in immunization programs are very important if high coverage is to be sustained over the years to reduce vaccine preventable diseases. ${ }^{6}$ Measles and poliomyelitis vaccine coverage in some African countries has improved as a result of administrative, technical, and financial support from bilateral or multilateral agencies such as United Nations International Children's Emergency Fund (UNICEF),GAVI and World Health Organization. ${ }^{7}$

Consequently, some sub-Saharan African countries have experienced a reversal in gains after a long period of great progress towards eliminating vaccine-preventable childhood diseases. A large measles outbreaks in the Democratic Republic of the Congo exemplified this. ${ }^{8}$ Vaccination uptake and coverage in African countries continue to vary for example DTP3 coverage ranged from $56 \%$ in Nigeria to $97 \%$ in the Gambia based on the study conducted by Jacob S. Kazungu et al 2017. ${ }^{9}$
The review of various demographic health survey of west african countries indicate variations in vaccine coverage and uptake. A primary qualitative study conducted by Li et al 2020 in Kenya Health facilities indicate that empowering health care workers and care givers with immunization information will boost and have positive impact on vaccine confidence and uptake. ${ }^{10}$

\section{THE FOLLOWING ARE AMONG THE FACTORS THAT INFLUENCING CHILDHOOD VACCINE UPTAKE}

Maternal education: Maternal education is thought to be one important factor that influences vaccine uptake in low-income countries. A recent systematic review demonstrated that educated mothers, regardless of the level of education, are more likely to have their children vaccinated. ${ }^{11}$ Another population based study conducted in Eritrea demonstrated that mothers who attended primary level of education were more likely to have their children fully vaccinated than mothers who have not received any education. ${ }^{12}$ A study conducted in Norway found out that HPV vaccine initiation increased with increasing maternal income. Also, HPV vaccination initiation was higher among girls with mothers of low education. ${ }^{13,14}$

However, in Africa, there are some factors which undermine female education such as early marriages and pregnancies. It is reported that about $40 \%$ of girls will get married before the age of 18years and African countries account for high proportion of child marriages worldwide. ${ }^{15}$ Many girls are forced into early marriages due to cultural stigmatization. ${ }^{16}$ Many African countries have made commitments to move towards universal / compulsory primary education for girls to keep them long in schools and avoid 
Table 1. Cross-comparison of vaccine hesitancy and uptake in Africa regions

\begin{tabular}{|l|l|l|c|}
\hline Author & $\begin{array}{l}\text { Year of } \\
\text { publication }\end{array}$ & \multicolumn{1}{c|}{ Title } & Country \\
\hline Sara Cooper et al & 2018 & $\begin{array}{l}\text { Vaccine hesitancy - a potential threat to the achievements of vaccination } \\
\text { programs in Africa }\end{array}$ & Africa \\
\hline Linda K. Ko et al & 2019 & $\begin{array}{l}\text { A qualitative study of perceptions of HPV vaccine and vaccine uptake } \\
\text { among East African immigrant mothers }\end{array}$ & $\begin{array}{l}\text { East } \\
\text { africa }\end{array}$ \\
\hline $\begin{array}{l}\text { Aanuoluwapo } \\
\text { Adeyimika Afolabi } \\
\text { et al. }\end{array}$ & 2021 & $\begin{array}{l}\text { Dealing with vaccine hesitancy in Africa: the prospective COVID-19 } \\
\text { vaccine context }\end{array}$ & Africa \\
\hline $\begin{array}{l}\text { Ingrid T. Katz et al } \\
\text { Jacob S. Kazungu } \\
\text { et al }\end{array}$ & 2013 & $\begin{array}{l}\text { A Qualitative Analysis of Factors Influencing HPV Vaccine Uptake in } \\
\text { Soweto, South Africa among Adolescents and Their Caregivers }\end{array}$ & $\begin{array}{l}\text { South } \\
\text { Africa }\end{array}$ \\
\hline
\end{tabular}

early female marriages. Countries such as Zambia, Cameroon and South Africa started implementing re-entry policies so that mothers can return to school after giving birth. However, young mothers usually have no financial support to be enrolled to school and face isolation in school. ${ }^{17}$ For example, a study conducted in Ethiopia in the Ambo region found that while more than half of the mothers knew the importance of vaccination, few of them knew the age at which childhood vaccination should be initiated. 18

Political instabilities: Childhood vaccination uptake has been affected by political instabilities, especially civil wars. This disrupts vaccination programs and prevents children from being fully vaccinated. ${ }^{19}$ Restoration of routine immunizations takes long because of the destruction of health care facilities during wars. For example, DRC Congo continues experiencing conflicts between the armed militia groups, FDLR and Mai Mai militia. ${ }^{20}$ In Sub-Saharan African countries, such as Libya, where there has been armed conflict, health care systems have been rendered fragile. ${ }^{21}$

Reliance of foreign aid to fund vaccine procurement and delivery: African countries depend heavily on development partners for assistance in health care. Health care assistance is channeled through multinational agencies such as Global alliance for vaccine and immunization (GAVI), World Health Organization (WHO) and United Nation Children Fund (UNICEF). GAVI alone fully finances all supplementary immunization activities doses in 73 countries. ${ }^{22}$ This model of financing immunization program is not sustainable and is currently facing unprecedented financial constraints due to recession during the COVID-19 pandemic.

Vaccine coverage and hesitancy: Across the world, vaccines are an effective tool to control and eliminate diseases. Some people, however, perceive vaccines as unsafe and unnecessary. Vaccine coverage and hesitancy vary from country to country and region to region for example the study conducted by James Bao et al 2018- indicate how Rwanda had achieved $98 \%$ vaccination coverage 23 On contrary, this may not be the case in other african countries for example a study conducted in Nigeria by Sulaimon T. Adedokun et al 2017 revealed that vaccine hesitancy was attributed by individual and state level factors which influenced the risk of children being incompletely immunized in Nigeria. ${ }^{24}$ The problem of vaccine hesitancy, uptake and coverage is cross cutting issue and its magnitude vary from one region depending on each country specific policy measures towards vaccination. Therefore, factors influencing vaccine coverage, uptake and hesitancy do not affects African countries in the same way due to the nature of individual and state level settings.

Religion: Religious factors are key determinants of vaccine uptake in some countries of sub-Saharan Africa. Muslim families have been reported to have low vaccine uptak. ${ }^{25}$ A study conducted in rural Nigeria revealed that full vaccination coverage was two-fold higher among children from non-Muslim families than children from Muslim families (Ayo Adebowale et al 2019). In another study conducted in Nigeria reported that Muslims opposed immunization because they had a belief immunization threatened the welfare of their communities. ${ }^{25}$ This problem is not limited to the Muslim community only. Another example in developed countries is the orthodox Christian community in Netherlands where the results show low immunization uptake. ${ }^{26}$

Distance and geographical location: Most people in Africa live in rural areas where health care service is not easily accessible. ${ }^{27}$ In rural setting, childhood vaccination is hampered by low staffing and poor logistics. In addition, about $16 \%$ of rural villages do not have mobile vaccination programs because of a lack of transportation infrastructure and more than half of rural health centers experience vaccine shortage. ${ }^{28}$ Due to the foregoing challenges urban vaccination campaigns are more successful (higher immunization coverage) than in rural settings. ${ }^{29}$

Economic factors: There is an association between principal economic activities of a parent and full vaccination uptake. Poor and unemployed parents may not be able to pay health care cost unlike parents who are employed. The study findings show that there is a difference in economic conditions of household and vaccination coverage. Economic gap of households will influence vaccination uptake in most cases. ${ }^{30}$ In areas of high economic quartile, there is a better immunization coverage rate and high chances of being vaccinated. Some of the reasons which mothers give for not vaccinating their children is that they lack money for these services. Some countries have good health insurance 
policy like Rwanda where there is easy access of health care services. ${ }^{31}$

Emerging challenges: The COVID-19 pandemic has disrupted health activities and caused social economic and political stress. Countries are facing low routine vaccination rates as compared to the situation before the COVID-19 pandemic. A study conducted recently showed the devasting impact of COVID-19 pandemic on routine immunization in Africa. ${ }^{32}$ Another study revealed that the Indonesian government is struggling to maintain immunization budget amidst the pandemic. ${ }^{33}$

\section{CONCLUSIONS}

Countries must address their local vaccination failures and problems through prioritizing funding for access to vaccine, strengthen large capacity vaccine coverage storage, maintain effective cold chain, improve on their research centers, and address vaccine hesitancy while identifying priority population for vaccination. Intensive community engagement and effective health communication are needed to disseminate accurate information and facilitate optimal vaccine uptake.

\section{FUNDING}

None.

\section{AUTHORSHIP CONTRIBUTIONS}

All authors contributed to the manuscript.

\section{COMPETING INTERESTS}

The authors completed the Unified Competing Interest form at http://www.icmje.org/disclosure-of-interest/ (available upon request from the corresponding author) and declare no conflicts of interest.

\section{CORRESPONDENCE TO:}

Mbonigaba Edward, Heidelberg Institute of Global Health, University of Heidelberg, Germany. edwardnkwaya@gmail.com

Submitted: May 14, 2021 GMT, Accepted: June 23, 2021 GMT 


\section{REFERENCES}

1. Andre F, Booy R, Bock H, et al. Vaccination greatly reduces disease, disability, death and inequity worldwide. Bull World Health Organ.

2008;86(2):140-146. doi:10.2471/BLT.07.040089

2. Bangura JB, Xiao S, Qiu D, Ouyang F, Chen L. Barriers to childhood immunization in sub-Saharan Africa: A systematic review. BMC Public Health. 2020;20(1):1108. doi:10.1186/s12889-020-09169-4

3. Vikram K, Vanneman R, Desai S. Linkages between maternal education and childhood immunization in India. Soc Sci Med 1982. 2012;75(2):331-339. doi:10.1 016/j.socscimed.2012.02.043

4. Greenwood B. The contribution of vaccination to global health: past, present and future. Philos Trans $R$ Soc B Biol Sci. 2014;369(1645). doi:10.1098/rstb.201 $\underline{3.0433}$

5. Duclos P, Okwo-Bele JM, Gacic-Dobo M, Cherian T. Global immunization: status, progress, challenges and future. BMC Int Health Hum Rights. 2009;9(1):S2. doi:10.1186/1472-698X-9-S1-S2

6. Feldstein LR, Mariat S, Gacic-Dobo M, Diallo MS, Conklin LM, Wallace AS. Global Routine Vaccination Coverage, 2016. MMWR Morb Mortal Wkly Rep. 2017;66(45):1252-1255. doi:10.15585/mmwr.mm6645 a3

7. Miller MA, Sentz JT. Vaccine-Preventable Diseases. In: Jamison DT, Feachem RG, Makgoba MW, et al., eds. Disease and Mortality in Sub-Saharan Africa. 2nd ed. World Bank; 2006. Accessed April 27, 2021. htt p://www.ncbi.nlm.nih.gov/books/NBK2284/

8. Grout L, Minetti A, Hurtado N, et al. Measles in Democratic Republic of Congo: an outbreak description from Katanga, 2010-2011. BMC Infect Dis. 2013;13(1):232. doi:10.1186/1471-2334-13-232

9. Kazungu JS, Adetifa IMO. Crude childhood vaccination coverage in West Africa: Trends and predictors of completeness. Wellcome Open Res. 2017;2. doi:10.12688/wellcomeopenres.10690.1

10. Li AJ, Tabu C, Shendale S, et al. Qualitative insights into reasons for missed opportunities for vaccination in Kenyan health facilities. PLOS ONE. 2020;15(3):e0230783. doi:10.1371/journal.pone.0230 $\underline{783}$
11. Forshaw J, Gerver SM, Gill M, Cooper E, Manikam $\mathrm{L}$, Ward $\mathrm{H}$. The global effect of maternal education on complete childhood vaccination: a systematic review and meta-analysis. BMC Infect Dis. 2017;17. doi:10.11 $\underline{86 / \mathrm{s} 12879-017-2890-\mathrm{y}}$

12. Kibreab F, Lewycka S, Tewelde A. Impact of mother's education on full immunization of children aged 12-23 months in Eritrea: population and health survey 2010 data analysis. BMC Public Health. 2020;20(1):267. doi:10.1186/s12889-020-8281-0

13. Brewer NT, Gottlieb SL, Reiter PL, et al. Longitudinal Predictors of HPV Vaccine Initiation among Adolescent Girls in a High-Risk Geographic Area. Sex Transm Dis. 2011;38(3):197-204. doi:10.109 7/OLO.0b013e3181f12dbf

14. Hansen BT, Campbell S, Burger E, Nygård M. Correlates of HPV vaccine uptake in school-based routine vaccination of preadolescent girls in Norway: A register-based study of 90,000 girls and their parents. Prev Med. 2015;Aug 1(7):4-10.

15. Mulenga J, Mulenga MC, Bwalya BB, NgongolaReinke $C$. Too young to be a wife! analysis of the factors influencing child marriages and its influence on the preferred number of children among women in Zambia. Afr Popul Stud. 2018;32(2). doi:10.11564/3 $\underline{2-2-1210}$

16. Lilian G, Nancy I, Odundo P, Akondo J, Ngaruiya B. Early and Forced Child Marriage on Girls' Education, in Migori County, Kenya: Constraints, Prospects and Policy. World J Educ. 2015;5. doi:10.543 0/wje.v5n4p72

17. Tuwor T, Sossou MA. Gender discrimination and education in West Africa: strategies for maintaining girls in school. Int J Incl Educ. 2008;12(4):363-379. do i: $10.1080 / 13603110601183115$

18. Tadesse H, Deribew A, Woldie M. Predictors of defaulting from completion of child immunization in south Ethiopia, May 2008 - A case control study. BMC Public Health. 2009;9(1):150. doi:10.1186/1471-245 $\underline{8-9-150}$

19. Abdullahi MF, Stewart Williams J, Sahlèn KG, Bile $\mathrm{K}$, Kinsman J. Factors contributing to the uptake of childhood vaccination in Galkayo District, Puntland, Somalia. Glob Health Action. 13(1). doi:10.1080/16549 716.2020.1803543 
20. Deressa W, Kayembe P, Neel AH, Mafuta E, Seme A, Alonge O. Lessons learned from the polio eradication initiative in the Democratic Republic of Congo and Ethiopia: analysis of implementation barriers and strategies. BMC Public Health. 2020;20(Suppl 4). doi:10.1186/s12889-020-09879-9

21. Ghobarah HA, Huth P, Russett B. The post-war public health effects of civil conflict. Soc Sci Med 1982. 2004;59(4):869-884. doi:10.1016/i.socscimed.20 $\underline{03.11 .043}$

22. Ozawa S, Grewal S, Portnoy A, et al. Funding gap for immunization across 94 low- and middle-income countries. Vaccine. 2016;34(50):6408-6416. doi:10.101 6/j.vaccine.2016.09.036

23. Bao J, McAlister H, Robson J, et al. Near universal childhood vaccination rates in Rwanda: how was this achieved and can it be duplicated? Lancet Glob Health. 2018;6:S47. doi:10.1016/S2214-109X(18)30176-1

24. Adedokun ST, Uthman OA, Adekanmbi VT, Wiysonge CS. Incomplete childhood immunization in Nigeria: a multilevel analysis of individual and contextual factors. BMC Public Health. 2017;17(1):236. doi:10.1186/s12889-017-4137-7

25. Jegede AS. What Led to the Nigerian Boycott of the Polio Vaccination Campaign? PLOS Med. 2007;4(3):e73. doi:10.1371/journal.pmed.0040073

26. Paulussen TG, Hoekstra F, Lanting CI, Buijs GB, Hirasing RA. Determinants of Dutch parents' decisions to vaccinate their child. Vaccine. 2005;24(5):644-651. doi:10.1016/j.vaccine.2005.08.05 3

27. Malison MD, Sekeito P, Henderson PL, Hawkins RV, Okware SI, Jones TS. Estimating health service utilization, immunization coverage, and childhood mortality: a new approach in Uganda. Bull World Health Organ. 1987;65(3):325-330.
28. Kaboré S, Kaboré BYL, Ouédraogo SYYA, et al. [Equity of access to immunization services in the Center-East health region in 2018, Burkina Faso]. Sante Publique Vandoeuvre--Nancy Fr.

2020;32(2):263-272. doi:10.3917/spub.202.0263

29. Sanou A, Simboro S, Kouyaté B, Dugas M, Graham J, Bibeau G. Assessment of factors associated with complete immunization coverage in children aged 12-23 months: a cross-sectional study in Nouna district, Burkina Faso. BMC Int Health Hum Rights. 2009;9(Suppl 1):S10. doi:10.1186/1472-698X-9-S1-S1 $\underline{0}$

30. Zuber PL, Conombo KS, Traoré AD, et al. Mass measles vaccination in urban Burkina Faso, 1998. Bull World Health Organ. 2001;79(4):296-300.

31. Nyandekwe M, Nzayirambaho M, Kakoma JB. Universal health insurance in Rwanda: major challenges and solutions for financial sustainability case study of Rwanda community-based health insurance part I. Pan Afr Med J. 2020;37. doi:10.1160 4/pamj.2020.37.55.20376

32. Abbas K, Procter SR, van Zandvoort K, et al. Benefit-Risk Analysis of Health Benefits of Routine Childhood Immunisation against the Excess Risk of SARS-CoV-2 Infections during the COVID-19 Pandemic in Africa. Epidemiology. Published online 2020. doi:10.1101/2020.05.19.20106278

33. Suwantika AA, Boersma C, Postma MJ. The potential impact of COVID-19 pandemic on the immunization performance in Indonesia. Expert Rev Vaccines. 2020;19(8):687-690. doi:10.1080/1476058 4.2020.1800461 